\title{
IMPLEMENTASI JARINGAN SENSOR NIRKABEL MENGGUNAKAN ZIGBEE PADA MONITORING TABUNG INKUBATOR BAYI
}

\author{
Fathur Zaini Rachman \\ Jurusan Teknik Elektronika, Politeknik Negeri Balikpapan \\ Corresponding author, e-mail : fozer85@gmail.com
}

\begin{abstract}
Abstrak-Implementasi jaringan sensor nirkabel menggunakan zigbee bertujuan untuk memudahkan komunikasi antara pengguna (perawat) dengan sistem yang sedang beroprasi pada tabung inkubator bayi. Selain itu, perawat dapat selalu memantau kondisi tabung inkubator bayi walaupun berada di ruang perawat. Pada penelitian ini terdiri dari tiga bagian utama, pertama modul sensor menggunakan SHT11 sebagai pendeteksi suhu dan kelembaban tabung inkubator bayi, kedua jaringan nirkabel menggunakan ZigBee sebagai media komunikasi antara modul sensor dengan komputer, ketiga HMI (Human Machine Interface) pada komputer sebagai pengolah data yang diterima dari setiap modul sensor yang tersebar. Hasil dari penelitian ini didapatkan bahwa sistem dapat berkerja dengan semestinya dengan topologi star, sehingga komunikasi ini sangat baik bila diterapkan pada ruang lingkup yang masih dijangkau oleh end device dan coordinator. Adapun untuk ruang lingkup yang lebih luas dapat menggunakan topologi mesh dengan menambahkan router pada titik jangkauannya.
\end{abstract}

\section{Kata Kunci : Modul Sensor, Jaringan Nirkabel, Human Machine Interface}

\begin{abstract}
Implementation of wireless sensor networks using zigbee to facilitate communication between users (nurse) with systems that operate on tube baby incubator. In addition, nurses can always monitor the condition of tube baby incubator at the nursing station. In this study consists of three main parts, the first sensor module using SHT11 as detection of temperature and humidity tube baby incubator, the second wireless network using ZigBee as a medium of communication between the sensor module with a computer, a third HMI (Human Machine Interface) on the computer as a data processor which received from each sensor module scattered. The results of this study found that the system can work properly with a star topology, so communication was very good when applied to the scope of which is still to reach by the end device and the coordinator. As for the broader scope can use a mesh topology to add a router at the point range.
\end{abstract}

Keywords : Sensor module,wirelessnetwork, Human Machine Interface.

Copyright $\odot 2016$ JNTE. All rights reserved

\section{PENDAHULUAN}

Inkubator bayi adalah salah satu alat medis yang digunakan untuk menjaga kestabilan suhu dalam tabung inkubator secara berkala. Terutama Bayi prematur umumnya perlu diletakkan pada tabung inkubator yang mempunyai sistem pengontrol suhu dan kelembaban, sehingga kestabilan suhu bayi dapat dijaga. Faktor - faktor yang perlu diperhatikan pada inkubator adalah suhu inkubator, suhu bayi, dan kelembaban dalam tabung inkubator.

Pada saat ini banyak terjadi kecelakaan pada bayi di tabung inkubator, yang menyebabkan bayi mengalami kepanasan hingga bayi meninggal dunia. Faktor kejadian ini terjadi karena beberapa hal, salah satunya sistem kendali suhu dan kelembaban pada tabung inkubator bayi sudah tidak beroprasi dengan baik. Selain itu belum adanya peringatan berupa informasi jika tabung inkubator bayi bermasalah, sehingga penanganannya oleh perawat menjadi lambat.

Pada penelitian ini, bertujuan untuk mencegah kejadian yang serupa dengan suatu perangkat yang dapat mengukur suhu dan kelembaban sebagai back up informasi tabung inkubator bayi, dan untuk pemasangan perangkat agar supaya lebih mudah dan hemat energi maka dibutuhkan suatu komunikasi data dari titik pemasangan sebagai pengiriman data ke titik penerimaan sebagai pengolahan data oleh komputer. Selain itu untuk penangan oleh 
perawat agar lebih maksimal dari segi penanggulangan kecelakaan digunakan komputer sebagai HMI (Human Machine Interface) untuk memantau kondisi tabung inkubator bayi secara berkala. Agar dapat menjaga kestabilan suhu tubuh bayi dalam batas normal antara $36^{\circ} \mathrm{C}-37^{\circ} \mathrm{C}$.

\section{TINJAUAN PUSTAKA}

\subsection{Inkubator Bayi}

Inkubator Bayi merupakan salah satu alat medis yang berfungsi untuk menjaga suhu sebuah tabung supaya suhu tetap stabil. Pada modifikasi inkubator bayi, terdapat sebuah kendali yang dibagi menjadi 2 bagian (bagian atas dan bagian bawah). Bagian atas digunakan untuk meletakkan sensor, tampilan informasi sensor, kendali dan rangkaian elektronik. Sedangkan pada bagian bawah dibagi menjadi 3 bagian yang dibatasi dengan sekat yang digunakan untuk meletakkan pemanas, wadah air dan kipas. Contoh tabung inkubator di rumah sakit dapat dilihat pada Gambar 1.

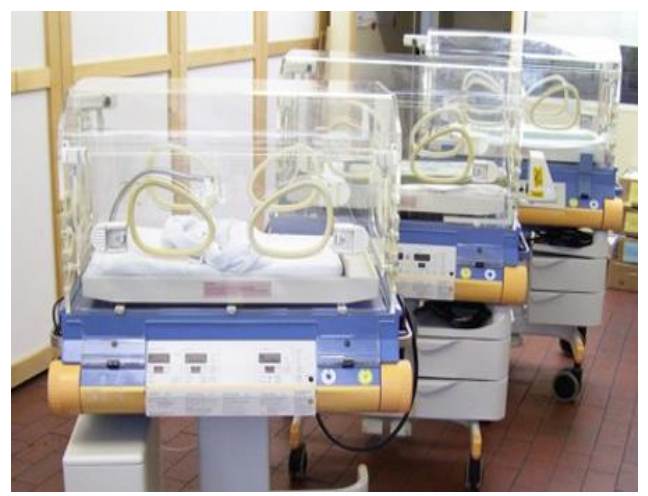

Gambar 1. Tabung Inkubator Bayi

Contoh Gambar 1 merupakan contoh peletakkan tabung inkubator diruangan pada rumah sakit pada umumnya.

\subsection{Modul Sensor}

Modul sensor SHT11 seperti pada Gambar 2 memiliki fungsi yaitu sebagai pendeteksi suhu dan kelembaban, selain itu sebagai titik pengiriman data ke komputer. Pada bagian pendeteksi suhu dan kelembaban menggunakan sensor SHT11, hubungan antara mikrokontroler dengan SHT11, dimana mikrokontroler berfungsi sebagai master dan SHT11 sebagai slave. Sensor SHT11 memiliki alamat 00000101 biner atau 05 hexadesimal dan untuk mengakses kelembaban dan 00000011 biner atau 03 hexadesimal untuk mengakses temperatur. Data yang diterima mikrokontroler dari SHT11 berupa data serial, karena SHT11 memiliki ADC (Analog to Digital Converter) sehingga data yang dikirim sudah berupa data digital. Hasil pengolahan data oleh mikrokontroler ditampilkan juga pada LCD (Liquid Cristal Display) yang berfungsi untuk tampilan pengaturan suhu dan kelembaban di tabung inkubator.

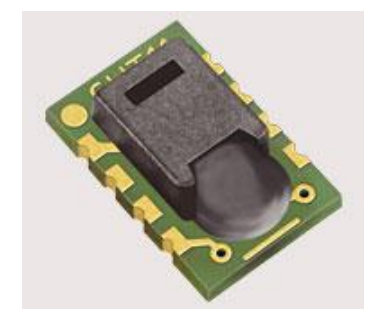

\section{Gambar 2. Sensor SHT11}

\subsection{ZigBee dan Topologi Jaringan}

ZigBee adalah standar yang menetapkan seperangkat protokol komunikasi untuk data rate rendah pada jaringan nirkabel jarak pendek. Perangkat nirkabel berbasis ZigBee beroperasi pada band frekuensi $868 \mathrm{MHz}, 915 \mathrm{MHz}$ dan 2,4 GHz. Data maksimum adalah $250 \mathrm{Kbps}$. Bentuk fisik Zigbee seperti pada Gambar 3 [1].

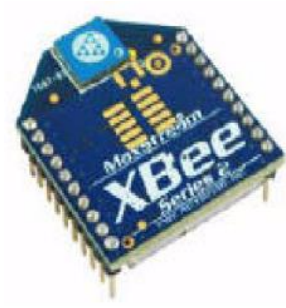

Gambar 3. Zigbee

Dalam media komunikasi nirkabel menggunakan ZigBee, jaringan ini memiliki 2 topologi yaitu topologi star dan topologi mesh. Dalam topologi star seperti pada Gambar 4 atau biasa disebut juga dengan nama point to point terdiri dari end device dan coordinator, dalam topologi ini semua perangkat berkomunikasi langsung ke coordinator, sehingga komunikasi ini sangat baik bila diterapkan pada ruang lingkup yang masih dijangkau oleh end device dan coordinator [2]. 


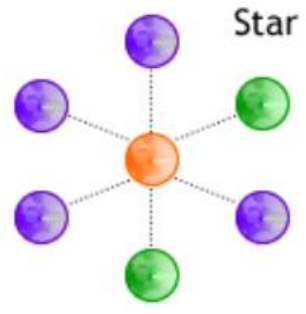

Gambar 4. Topologi Star

Sedangkan pada topologi mesh biasa disebut juga peer to peer yang terdiri dari end device, router dan coordinator. Dalam topologi mesh seperti pada Gambar 5, digunakan dalam penerapan jangkauan yang lebih luas ketimbang pada topologi star. Dimana, area yang tidak terjangkau dapat ditangani dengan menggunakan router dalam pengiriman dan penerimaan data antara end device dengan coordinator. Selain itu, pada topologi mesh dapat mendukung komunikasi multi-hop sehingga sinyal yang lemah dapat ditangani dengan menggunakan perangkat router sebagai jembatan penghubung $[3,4]$.

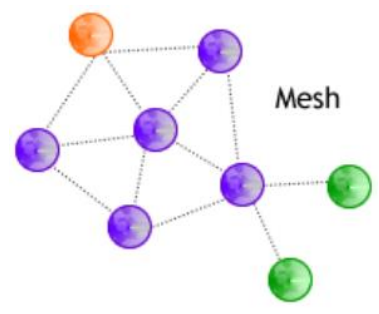

Gambar 5. Topologi Mesh

\subsection{WSN (Wireless Sensor Network)}

WSN atau jaringan sensor nirkabel adalah kumpulan sejumlah node yang diatur dalam sebuah kerjasama jaringan [5]. Arsitektur umum pada perangkat sensor nirkabel pada Gambar 6 .

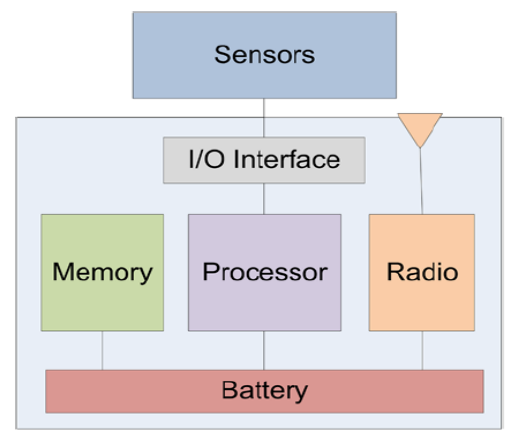

Gambar 6. Arsitektur dari node WSN
Setiap node setidaknya memiliki fungsi perhitungan, komunikasi nirkabel, dan pengindraan atau fungsi kendali [6]. Banyak aplikasi yang dapat dilakukan menggunakan WSN , misalnya dalam pengumpulan data pada kondisi suatu lingkungan, pengamatan keamanan dan sistem pelacak keberadaan node [7]. WSN ini telah diterapkan pada aplikasi sistem keamanan di rumah sakit [8]. Sejumlah rumah sakit dan pusat kesehatan menggunakan aplikasi teknologi WSN untuk berbagai aplikasi medis, dengan melakukan pengumpulan datadata penting pasien yang terintegrasi secara otomatis terekam ke dalam catatan perawatan pasien, korelasi dengan catatan rumah sakit, dan pengamatan jangka panjang, sehingga data-data tersebut menjadi database klinis. Hal ini memungkinkan dokter untuk mempelajari efek dari program intervensi medis.

\subsection{HMI (Human Machine Interface)}

Untuk mempermudah perawat atau penjaga dalam melakukan monitoring maka diperlukan program aplikasi dalam bentuk HMI dengan bantuan software Visual Basic seperti pada Gambar 7. HMI merupakan tampilan dari analisa dan pengolahan data oleh coordinator, dimana coordinator yang letaknya pada komputer menangkap paket data yang ada pada modul sensor. Tampilan HMI ini akan memberikan informasi keadaan tabung inkubator kepada perawat dalam mengetahui keadaan suhu dan kelembaban tabung, sehingga perawat tidak perlu lagi harus memantau secara berkala ketempat pamasangan, dan apabila terjadi sesuatu pada tabung inkubator maka dapat segera diketahui dan ditangan dengan cepat, karena pengiriman paket data yang ada pada modul sensor dikirim secara terus menerus dari titik modul sensor ke komputer sebagai pengolah data.

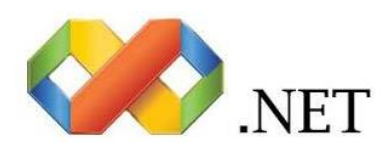

Gambar 7. Visual Basic Net

\section{METODOLOGI DAN TEORI}

Metodologi dimulai dengan perancangan, pembuatan perangkat hingga pengujian setiap bagian. Setelah pengujian dilakukan maka 
dilakukan pemasangan antar bagian untuk menguji kinerja alat yang dibuat.

\subsection{Perancangan Rangkaian}

Dalam perancangan terbagi menjadi 3 bagian pokok, seperti pada Gambar 8 .

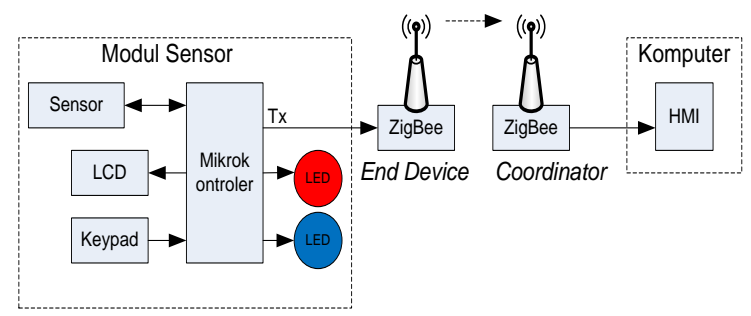

Gambar 8. Diagram Blok Sistem

3 bagian pokok tersebut, yaitu (1) modul sensor yang terletak pada tabung inkubator bayi, berfungsi sebagai pendeteksi atau pengindra suhu dan kelembapan yang diatur sesuai dengan masukkan pada keypad sehingga hasil dari pembacaan dapat dilihat pada LCD (Liquid Crystal Display) dan data yang ditampilan juga dikirim melalui komunikasi end device ke coordinator pada komputer. (2) ZigBee sebagai media komunikasi antar titik modul inkubator dalam mengirim data informasi ke komputer. (3) HMI (Human Machine Interface) sebagai pengolah informasi data dari setiap titik modul inkubator yang terpasang.

\subsection{Modul Sensor dan Cara Kerjanya}

Modul sensor terletak pada tabung inkubator, seperti pada Gambar 9.

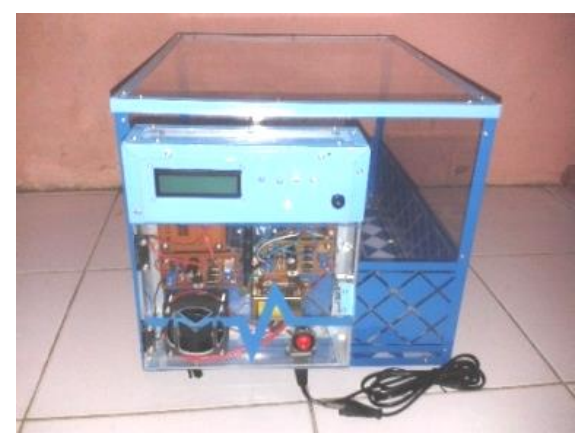

Gambar 9. Tabung Inkubator

Modul sensor terletak dibagian dalam pada tabung inkubator, dimana terintegrasi langsung ke mikrokontroler selalui jalur $\mathrm{I}^{2} \mathrm{C}$ Bus seperti pada Gambar 10.

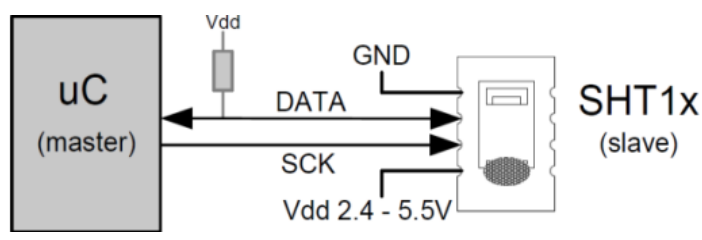

Gambar 10. Jalur I2C Bus mikrokontroler dengan sensor SHT11

Adapun cara kerja sistem pada mikrokontroler sebagai pemroses data seperti pada Gambar 11.

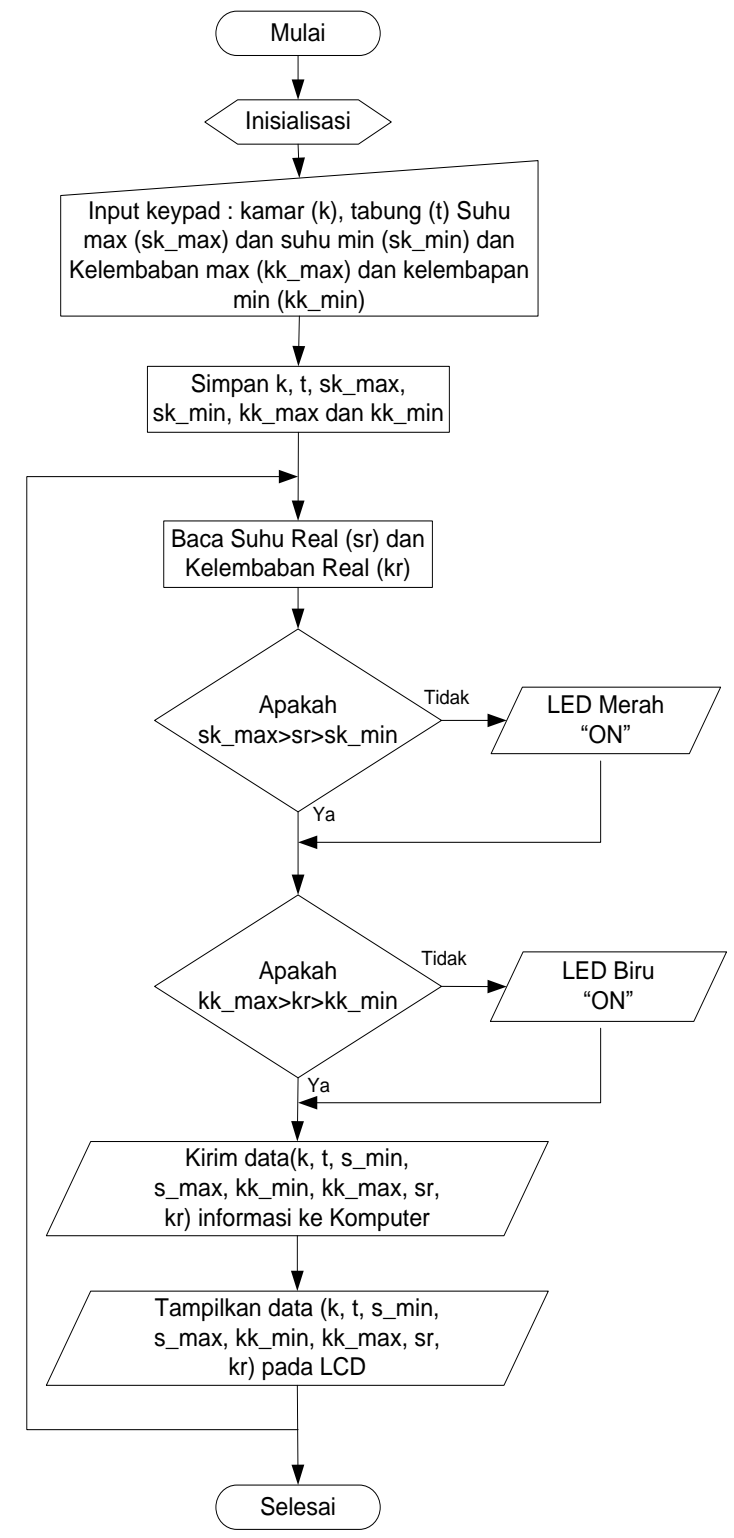

Gambar 11. Diagram Alir Kerja Sistem Modul Sensor 
Pada Gambar 11 menyatakan bahwa seorang perawat memasukkan informasi data berupa :

$$
\begin{aligned}
& \mathrm{k} \quad=\text { kamar } \\
& \mathrm{t} \quad=\text { tabung } \\
& \text { s_min }=\text { suhu minimum } \\
& \text { S_max }=\text { suhu maksimum } \\
& \text { kk_min }=\text { kelembapan minimum } \\
& \text { kk_max }=\text { kelembapan maksimum }
\end{aligned}
$$

setelah perawat memasukkan informasi maka data-data tersebut tersimpan, selanjutnya proses pembacaan suhu dan kelembapan yang dilakukan oleh mikrokontroler ke SHT11. Dimana :

$$
\begin{array}{ll}
\mathrm{sr} & =\text { suhu real } \\
\mathrm{kr} & =\text { kelembapan real }
\end{array}
$$

kemudian terjadi seleksi suhu dan kelembapan, jika suhu (sr) diatas suhu maksimum (s_max) atau suhu dibawah suhu minimum (s_min) yang ditentukan, maka LED merah "ON". Jika tidak, maka proses dilanjutkan ke seleksi kelembapan. Pada seleksi kelembapan, jika kelembapan (kr) diatas kelembapan maksimum (k_max) atau kelembapan dibawah kelembapan minimum (k_min) yang ditentukan, maka LED biru menyala "ON" dan dilanjutkan dengan pengiriman data informasi ke melalui pin $\mathrm{Tx}$ mikrokontroler. Jika tidak, maka data juga dikirim melalui pin $\mathrm{Tx}$ mikrokontoler dan ditampilkan pada LCD.

\subsection{Protokol Komunikasi}

Dalam sebuah sistem komunikasi dibutuhkan sebuah protokol agar dapat saling berkomunikasi, tujuannya adalah agar paket data yang diterima tidak terjadi kesalahan dalam menerima dan menentukan tidakan yang harus dilakukan selanjutnya pada bagian penerima dan ditampilkan dalam bentuk HMI (Human Machine Interface). Adapun bentuknya seperti pada Gambar 12.

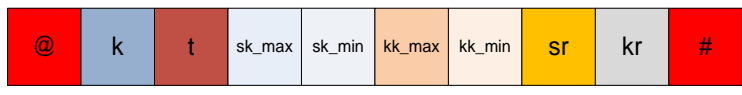

Gambar 12. Protokol Komunikasi

Gambar 12 menunujukkan urutan pengiriman data dan tabel I menunjukkan keterangan bahwa ukuran protokol yang digunakan adalah 16 byte.
Tabel 1. Simbol Protokol dan Ukurannya

\begin{tabular}{|c|c|c|}
\hline Simbol & $\begin{array}{c}\text { Ukuran } \\
\text { (Byte) }\end{array}$ & Keterangan \\
\hline $\mathrm{Q}$ & 1 & Start (Awal Protokol) \\
\hline $\mathrm{k}$ & 1 & Kamar \\
\hline $\mathrm{t}$ & 1 & Tabung \\
\hline sk_max & 2 & Suhu maksimum \\
\hline sk_min & 2 & Suhu minimum \\
\hline Kk_max & 2 & Kelembapan maksimum \\
\hline Kk_min & 2 & Kelembapan minimum \\
\hline sr & 2 & Suhu real (sensor) \\
\hline kr & 2 & Kelembapan real (sensor) \\
\hline$\#$ & 1 & End (Akhir Protokol) \\
\hline
\end{tabular}

\subsection{Jaringan Nirkabel ZigBee}

Pada topologi star semua perangkat berada dalam komunikasi langsung ke coordinator, dimana semua informasi data diarahkan. Skenario topologi star seperti terlihat pada Gambar 13.

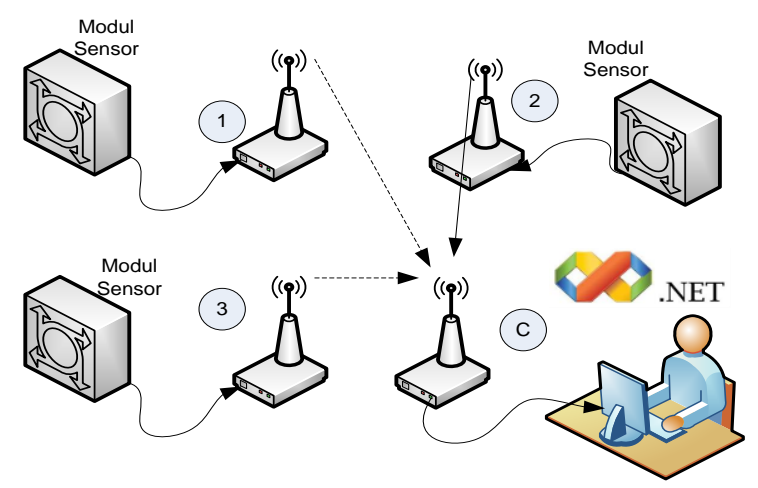

Gambar 13. Skenario Topologi Jaringan

Dalam skenario topologi star seperti pada Gambar 13, hal pertama dalam membangun sebuah jaringan adalah dengan membuat alamat sumber (MY) dan identitas jaringan (ID) pada coordinator PAN (Personal Area Network), pembuatan alamat sumber (MY) pada coordinator PAN bertujuan untuk memastikan alamat tujuan (DL) dari semua perangkat jaringan, sedangkan pembuatan identitas jaringan unik pada coordinator PAN bertujuan menjamin bahwa identitas jaringan PAN tidak digunakan oleh jaringan terdekat lainnya dalam kawasan radio, di mana di kawasan tersebut perangkat radio dapat berkomunikasi dengan radio lainnya. Langkah selanjutnya yaitu pembuatan alamat sumber (MY), alamat tujuan (DL) dan identitas jaringan (ID) pada semua 
perangkat. Adapun tujuan pembuatan alamat tujuan (DL) pada perangkat adalah untuk memastikan bahwa paket data dari perangkat dapat diterima oleh coordinator yang pada kali ini coordinator berperan sebagai pengumpul data dari semua yang perangkat dalam jaringan. Keterangan tentang konfigurasi jaringan seperti pada Tabel 2.

Tabel 2. Simbol Protokol dan Ukurannya

\begin{tabular}{|c|c|c|c|c|}
\hline Simbol & MY & DL & ID & Keterangan \\
\hline C & 1 & 0 & 999 & Coordinator \\
\hline 1 & 2 & 1 & 999 & End-Device \\
\hline 2 & 3 & 1 & 999 & End-Device \\
\hline 3 & 4 & 1 & 999 & End-Device \\
\hline
\end{tabular}

\subsection{Pengujian Jaringan Nirkabel}

Pengujian ini dilakukan di gedung (indoor), dimana untuk mengetahui jarak pengiriman dari perangkat sensor atau end device ke coordinator. Proses pengiriman data dilakukan dengan melakukan beberapa variasi jarak, sehingga didapatkan besar packet loss yang terjadi hingga $100 \%$ dengan jarak yang berbeda-beda. Pengujian komunikasi dilakukan pada transmisi indoor. Daya pancar yang digunakan dalam transmisi adalah $10 \mathrm{~mW}(10 \mathrm{dBm})$, RF Data Rate 1200 bps - 250 kbps. Adapun kemampuan sensitivitas penerima yaitu sebesar $-100 \mathrm{dBm}(1 \%$ packet error rate) [3].

\subsection{Tampilan Human Machine Interface}

HMI merupakan tampilan dari analisa dan pengolahan data dari coordinator, dimana coordinator menangkap paket informasi data yang ada pada modul sensor.

Tampilan HMI ini akan memberikan informasi keadaan tabung inkubator kepada perawat. Tampilan HMI seperti pada Gambar 14.

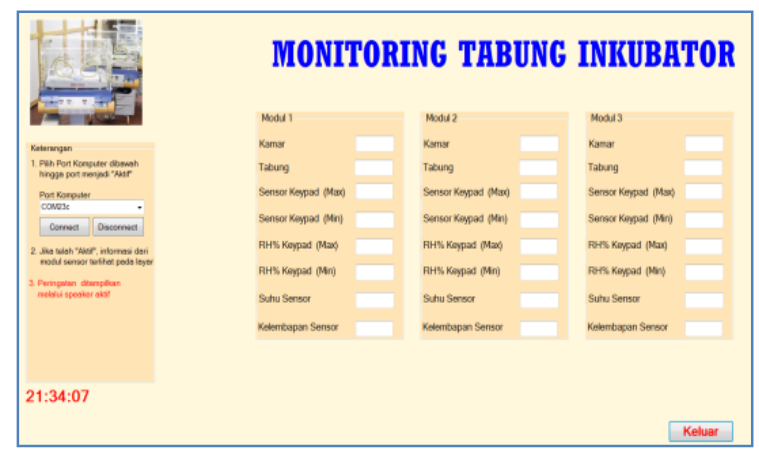

Gambar 14. Tampilan HMI
Adapun cara kerja sistem pada HMI seperti pada Gambar 15.

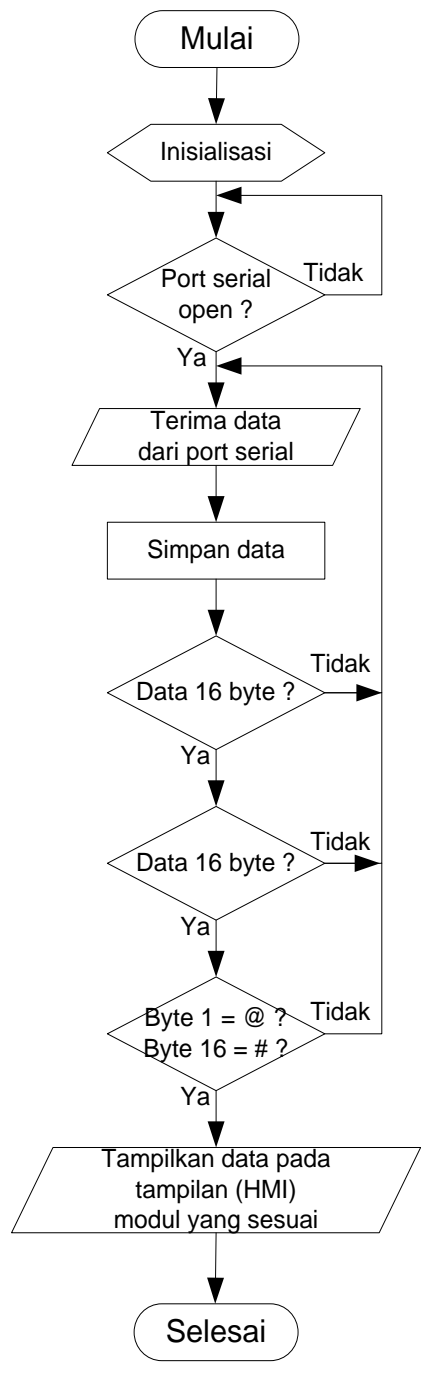

Gambar 15. Diagram Alir Sistem HMI

\section{HASIL DAN PEMBAHASAN}

Dalam pengujian dilakukan menjadi tiga bagian, yaitu dari modul sensor pada ruang inkubator, kinerja jaringan nirkabel zigbee dan kinerja coordinator pada komputer.

\subsection{Pengujian Modul Sensor SHT11}

Pengujian Modul sensor dilakukan dengan alat ukur suhu dan kelembapan dengan Hydrometer Thermometer KT908 . Pengujian suhu dilakukan dengan variasi suhu ruangan dan variasi kelembapan ruangan, dimana hasil pengujian suhu dapat dilihat pada Tabel 3 dan pengujian kelembapan dapat dilihat pada Tabel 4. 
Tabel 3. Hasil Pengujian Suhu

\begin{tabular}{|c|c|c|}
\hline \multicolumn{2}{|c|}{ Terukur $\left({ }^{\mathbf{}} \mathbf{C}\right)$} & \multirow{2}{*}{ Error \% } \\
\cline { 1 - 2 } $\begin{array}{c}\text { Alat Ukur } \\
(\text { KT908) }\end{array}$ & Sensor & 0 \\
\hline 25 & 25 & 0 \\
\hline 26 & 26 & 0 \\
\hline 27 & 27 & 0 \\
\hline 29 & 29 & 3,12 \\
\hline 32 & 33 & 0 \\
\hline 35 & 35 & 2,7 \\
\hline 37 & 36 & 0 \\
\hline 40 & 40 & 2,22 \\
\hline 45 & 46 & 1,88 \\
\hline 53 & 54 & \\
\hline
\end{tabular}

Tabel 4. Hasil Pengujian Kelembapan

\begin{tabular}{|c|c|c|}
\hline \multicolumn{2}{|c|}{ Terukur (RH) } & \multirow{2}{*}{ Error \% } \\
\cline { 1 - 2 } $\begin{array}{c}\text { Alat Ukur } \\
\text { (KT908) }\end{array}$ & Sensor & \\
\hline 41 & 41 & 0 \\
\hline 45 & 46 & 2,22 \\
\hline 49 & 50 & 2,04 \\
\hline 53 & 53 & 0 \\
\hline 55 & 55 & 0 \\
\hline 60 & 60 & 0 \\
\hline 63 & 65 & 3,17 \\
\hline 65 & 66 & 1,53 \\
\hline 70 & 71 & 1,42 \\
\hline 78 & 79 & 1,28 \\
\hline
\end{tabular}

Dari pengukuran terdapat error pada sensor, dengan demikian dapat dihitung nilai rata-rata error dengan persamaan berikut.

Rata-rata error $=\frac{1}{n} \sum_{i=1}^{n} x i$

Jadi, dari persamaan 1 didapatkan bahwa error rata-rata sensor suhu : 9,92/10 $=0,99 \%$, rata-rata sensor kelembapan: $11,66 / 10=1,16 \%$

Hasil pengujian sensor yang dilakukan terdapat error, dimana dikarenakan faktor floating yang mempengaruhi konversi pada mikrokontroler.

\subsection{Pengujian Kinerja Jaringan Nirkabel}

Daya pancar yang digunakan dalam transmisi adalah $10 \mathrm{~mW}(10 \mathrm{dBm})$, RF Data Rate 1200 bps - 250 kbps. Adapun kemampuan sensitivitas penerima yaitu sebesar $-100 \mathrm{dBm}(1 \%$ packet error rate). Pengujian dilakukan di dalam gedung (indoor)[4]. Hasil pengujian jaringan nirkabel zigbee seperti pada Tabel 5. Pengujian dilakukan dengan variasi ketinggian dan jarak. Dimana htx adalah tinggi dari perangkat pemancar yang mengirimkan paket data ke coordinator, yang pada pengujian ini dilakukan pada 5 kondisi yaitu 0 meter $(\mathrm{m}), 0,4 \mathrm{~m}, 0,8 \mathrm{~m}$, 1,2 $\mathrm{m}$ dan 1,6 m. Sedangkan pengujian jarak (d) adalah jauh antara perangkat dengan coordinator, yang pada pengujian ini jarak yang digunakan antara 0 sampai 60 meter. Dan packet loss adalah jumlah dari paket data yang gagal diterima oleh coordinator pada saat pengiriman dari perangkat.

Tabel 5. Pengujian Jaringan Nirkabel Nirkabel ZigBee

\begin{tabular}{|c|c|c|}
\hline $\begin{array}{l}\text { htx (perangkat) } \\
(\mathrm{m})\end{array}$ & $\begin{array}{c}\text { Jarak (d) } \\
(\mathrm{m})\end{array}$ & $\begin{array}{c}\text { Packet Loss } \\
(\%)\end{array}$ \\
\hline 0 & $\begin{array}{c}1-21 \\
22 \\
23-25 \\
26-27 \\
28 \\
29-34\end{array}$ & $\begin{array}{c}0 \\
13 \\
26 \\
8 \\
54 \\
100\end{array}$ \\
\hline 0,4 & $\begin{array}{c}1-29 \\
30-32 \\
33-34 \\
35-38 \\
39 \\
40-42 \\
43-48\end{array}$ & $\begin{array}{c}0 \\
5 \\
2 \\
16 \\
32 \\
63 \\
100\end{array}$ \\
\hline 0,8 & $\begin{array}{c}1-43 \\
44-47 \\
48-50 \\
51-53 \\
54 \\
55-60\end{array}$ & $\begin{array}{c}0 \\
20 \\
35 \\
47 \\
78 \\
100\end{array}$ \\
\hline 1,2 & $\begin{array}{c}1-49 \\
50 \\
51 \\
52-53 \\
54-55 \\
56 \\
57 \\
58 \\
59-64\end{array}$ & $\begin{array}{c}0 \\
7 \\
3 \\
25 \\
27 \\
38 \\
35 \\
40 \\
100\end{array}$ \\
\hline 1,6 & $\begin{array}{c}1-45 \\
46 \\
47 \\
48-49 \\
50-53 \\
54-55 \\
56-57 \\
58 \\
59-64\end{array}$ & $\begin{array}{c}0 \\
4 \\
7 \\
14 \\
24 \\
37 \\
43 \\
67 \\
100\end{array}$ \\
\hline
\end{tabular}


Adapun cara mengetahui packet loss, digunakan software X-CTU seperti pada Gambar 16.

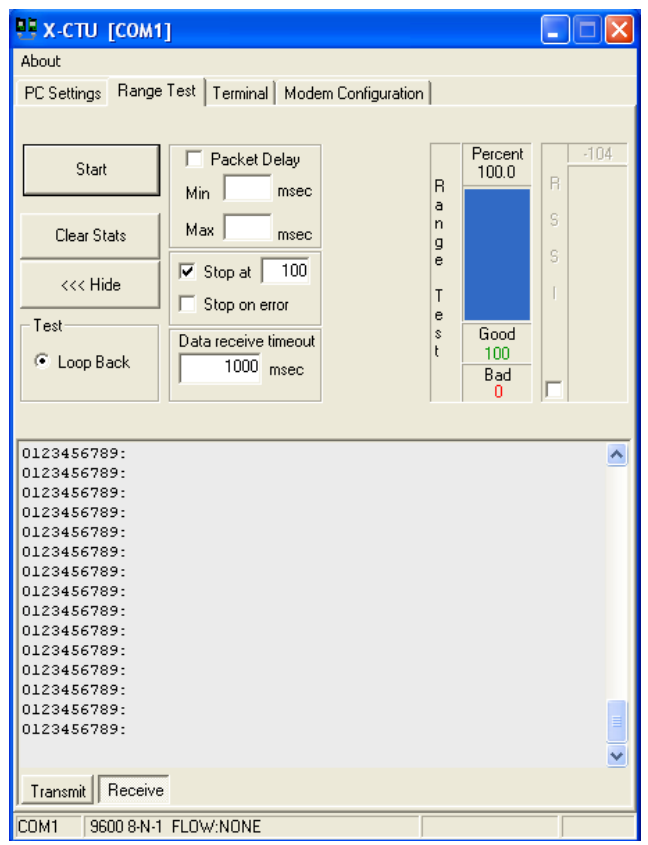

Gambar 16. X-CTU

\subsection{Pengujian Kinerja Coordinator}

Dalam pengujian kinerja coordinator dibagi menjadi 2 bagian, yaitu pengujian throughput dan packet loss.

\subsubsection{Pengujian Throughput Transmisi}

Throughput menunjukkan banyaknya data yang dapat diterima oleh coordinator dalam selang waktu tertentu, dimana throughput pada besarnya trafik yang terdapat pada jaringan. Throughput dapat dihitung dengan persamaan sebagai berikut [9].

$\operatorname{Tg}\left(\frac{\text { byte }}{\mathrm{s}}\right)=\frac{\text { byte data } * r x D P}{T(s)}$

Keterangan:

$$
\begin{array}{ll}
\mathrm{Tg} & =\text { Throughput } \\
\mathrm{rx} \mathrm{DP} & =\text { jumlah paket data yang diterima } \\
\mathrm{T} & =\text { waktu dalam detik }
\end{array}
$$

Pengujian throughput transmisi dibuat dalam bentuk grafik yang menyatakan bentuk perubahan disaat coordinator menerimaa paket data dari semua perangkat (perangkat modul sensor dan simulator) seperti pada Gambar 17.

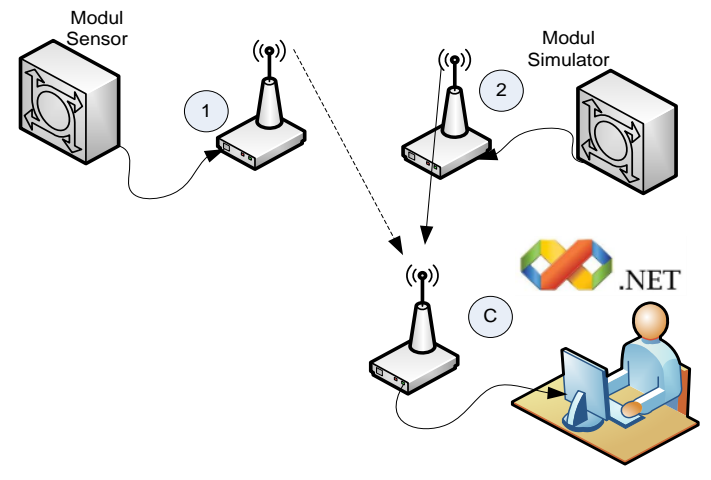

Gambar 17. Pengujian Throughput

Pada pengujian ini dilakukan 12 kali percobaan selama 60 detik, dimana modul sensor melakukan pengiriman data 16 byte dan modul simulasi melakukan pengiriman data yang bervariasi dari 16, 32, 48, 64, 80, 96, 112, 128, 144, 160, 176, 192 dan 208 byte. Pengujian dilakukan selama 1 menit dengan rata-rata throughput yang diterima pada coordinator seperti pada Gambar 18.

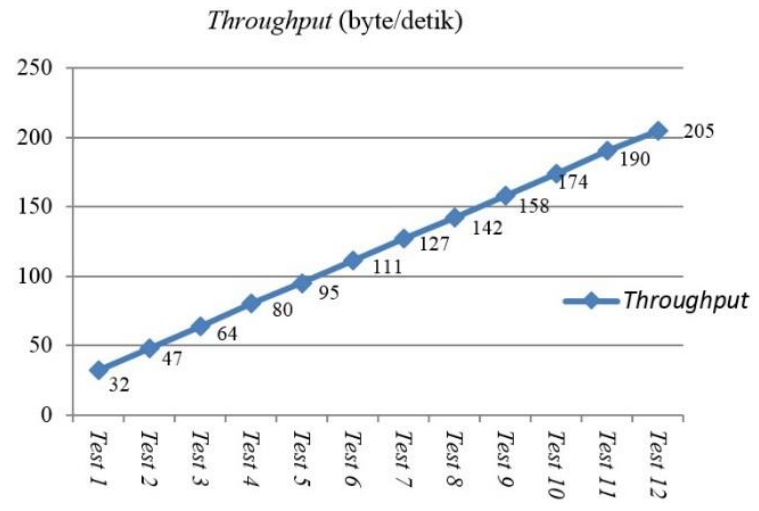

Gambar 18. Hasil Pengujian Throughput

Keterangan:

Test $n=16$ byte $+(16$ byte $x)$

Pada pengujian throughput diketahui semakin besar paket data yang dikirimkan dari modul sensor dan simulator ke coordinator maka packet loss akan semakin meningkat throughput data per detik yang diterima.

\subsubsection{Perhitungan Packet Loss}

Packet loss menunjukkan banyaknya data yang hilang sehingga paket data tidak diterima oleh coordinator dengan banyaknya data yang telah dikirim oleh perangkat pada satu 
pengukuran [10]. Perhitungan packet loss dalam presentasi dapat didefinisikan dengan persamaan berikut [11].

$P L_{T}=\left(1-\frac{n T r e c v}{n T \operatorname{sen} t}\right) \times 100 \%$

Packet loss didapatkan dari pengujian throughput yang menyatakan bentuk perubahan disaat coordinator menerima paket data dari semua perangkat jaringan. Hasil packet loss seperti pada Tabel 6 .

Tabel 6. Hasil Pengujian Packet Loss Throughput

\begin{tabular}{|c|c|c|}
\hline \multicolumn{2}{|c|}{ Byte } & \multirow{2}{*}{ P $L_{\boldsymbol{T}}(\%)$} \\
\hline nT recv & nT sent & \\
\hline 32 & 32 & 0 \\
\hline 47 & 48 & 2 \\
\hline 64 & 64 & 0 \\
\hline 80 & 80 & 0 \\
\hline 95 & 96 & 1 \\
\hline 111 & 112 & 0 \\
\hline 127 & 128 & 0,9 \\
\hline 142 & 144 & 1,4 \\
\hline 158 & 160 & 1,25 \\
\hline 174 & 176 & 1,28 \\
\hline 190 & 192 & 1 \\
\hline 205 & 206 & 0,5 \\
\hline
\end{tabular}

Dari pengukuran throughput terdapat packet loss dalam pengujian, dengan demikian dapat dihitung nilai rata-rata packet loss dengan persamaan berikut.

$$
\text { Rata-rata } P L_{T}=\frac{1}{n} \sum_{i=1}^{n} x i
$$

Jadi, dari persamaan 4 didapatkan bahwa rata-rata packet loss adalah 9,33/12 $=0,78 \%$. Hasil pengujian ini dikarenakan faktor floating yang mempengaruhi konversi pada mikrokontroler dan faktor noise saat pengiriman dan penerimaan data dititik pemasangan. Adapun kapasitas maksimum (bandwidth) pada jaringan adalah $250 \mathrm{Kbps}$ sesuai dengan data sheet perangkat ZigBee.

\section{KESIMPULAN}

Hasil pengujian sensor SHT11 yang dilakukan terdapat error $0,99 \%$ untuk suhu dan
$1,16 \%$ untuk kelembapan, ini dikarenakan faktor floating yang mempengaruhi konversi pada mikrokontroler.

Pada pengujian kinerja jaringan didaptkan ketinggian (htx) terbaik pada pemancar yang berada pada Perangkat (end device) terhadap coordinator (hrx) adalah 1,2 meter dari ketinggian permukaan lantai dengan jarak maksimum 49 meter.

Sedangkan pada pengujian pengiriman ke coordinator dengan variasi byte pengiriman data, dapat disimpulkan bahwa semakin besar paket data yang dikirimkan dari perangkat ke coordinator maka throughput akan semakin besar sampai kapasitas maksimal 250 Kbps.

Secara keseluruhan, sistem dapat berkerja dengan semestinya dengan topologi star, sehingga komunikasi ini sangat baik bila diterapkan pada ruang lingkup yang masih dijangkau oleh end device dan coordinator. Adapun untuk ruang lingkup yang lebih luas dapat menggunakan topologi mesh dengan menambahkan router pada titit jangkauan.

\section{DAFTAR PUSTAKA}

[1] Farahani, S., ZigBee Wireless Networks and Transceivers, Newnes (2008).

[2] Rachman, F.Z., Prototype development of monitoring system in patient infusion with wireless sensor network, ISITIA, Paper ID 453 (2015)

[3] Firdaus, Wireless Sensor Network; Teori dan Aplikasi, Graha Ilmu (2014).

[4] Labrador, M.A., Wightman, P.M. , Topology Control in Wireless Sensor Networks, Springer Science (2009)

[5] Hill, R. Szewczyk, A, Woo, S. Hollar, D. Culler, and K. Pister, System Architecture Directions for Networked Sensor, ASPLOS 2000

[6] Karl,H., Willig, A., Protocols and Architecture for Wireless Sensor Networks, Wiley (2005)

[7] Jason Lester Hill, System Architecture for Wireless Sensor Network, a dissertation in Computer Science in the Graduate Division of the University, Berkley (2003)

[8] Ville Kaseva, Timo D. H'am"al"ainen, and Marko H"annik"ainen, A Wireless Sensor Network for Hospital Security: From User Requirements to Pilot 
Deployment, EURASIP Journal on Wireless Communications and Networking, Volume 2011, Article ID 920141, doi:10.1155/2011/920141

[9] B. Preveze, A. Safak, Throughput Improvement of mobile multi-hop wireless network, Internasional Journal of Wireless \& Mobile Networks (IJWMN), vol.2, no.3, August 2010

[10] M. Shamsi, A.G Rahbar, Packet Loss Analysis of Multi-Fiber Asymmetric Share-per-link optical packet switches, Internasional Journal of Advances in Optical Communication and Network, Vol. 1, No.1, Des 2010

[11] M.S Koul, Analysis of The Effects of Packet Loss and Delay Jitter on MPEG-4 Video Quality, Dept. of Electric Engineering, Arlington, Texas

\section{Biodata Penulis}

Fathur Zaini Rachman, Menerima gelar S1 Elektro dari ITN Malang tahun 2009 dan gelar S2 Elektro ITS Surabaya 2011. Saat ini penulis sebagai dosen di Politeknik Negeri Balikpapan 